\section{Teller's cold comfort}

SIR - Turco et al. ${ }^{1}$ have performed a valuable service by bringing to public and political attention the probability that, in addition to the "known" effects of blast and radiation, large-scale nuclear war will cause severe climatic disturbance which could increase the number of fatalities. Expressed in those simple and general terms, their claim is unassailable but, without supporting argument, it would attract neither scientific nor political interest nor would it be intellectually satisfying to the authors.

Because there was detailed supporting argument, criticism of their assumptions and model was inevitable. Predictably there has been a rapid succession of publications describing alternative analyses of the likely climatic consequences of global nuclear war, no doubt motivated in part by an understandable academic desire to arrive at the correct conclusion and by some of the other attractions of publishing in the vanguard of a topic that is attracting wide public interest. I should emphasize that this motivation is academic rather than scientific since the proponents of the various models have less chance of testing them experimentally than proponents of some of the more esoteric theories of cosmology.

Of the articles I have seen, the one that alarms me most is that of Teller ${ }^{2}$. It is well argued, as one would expect, and apparently well supported factually. It is soothing in a way that the arguments from supporters of the nuclear industry often are. ("When the biological recovery formula is applied, a dose rate as high as 250 rem from worldwide fallout is built up at a rate so slow that it would not produce significant casualties". I do not wish to seem ungrateful, but this information does not make nuclear war any more appealing.)

In his introduction, Teller says: "Scientific knowledge of the after-effects of a nuclear war ... is of great importance in making political decisions". In his conclusion: "Therefore there is every reason to undertake the difficult task of arriving at more realistic predictions. ... Greater amounts of money, carefully spent on atmospheric modelling and experiments, would accelerate resolution of the basic questions regarding nuclear winter."

This, of course, is the substance of a cost-benefit analysis of nuclear war. With appropriate correction for distribution of bombs, the relation between mass of bombs exploded and the number of resulting deaths presumably resembles the Beer-Lambert spectrophotometric relation with a linear component for few bombs and a flattening of the curve for many bombs. If the "political decisions" of which Teller writes (I assume he means whether or not to bomb the Soviet Union) were to make any military sense, then the number of bombs used would have to be small enough to ensure that they were on the linear part of the death curve. Notwithstanding Teller's point about accurate low-yield missiles, that possibility seems very remote. Moreover, the correspondence about nuclear winter is specifically based on many bombs.

If it could be demonstrated that the predictions of a nuclear winter are exaggerated, how would that knowledge be used? Would one side bomb the other forthwith, secure in the knowledge that their few survivors would not be unduly cold, at least in summer? Or conversely, if the prediction is not exaggerated, does that mean that each side should stockpile food, as Teller suggests, so that the survivors can at least have some cold, albeit radioactive, porridge? If, in more comprehensive terms, the additional research for which Teller calls should conclude that a global war would not kill everyone, but merely 90 per cent of the world's population, would that make the war acceptable? The fine details of the ostensibly rational discussion about nuclear winter are fast making that discussion the penultimate insanity.

A.D. BROWN

Department of Biology,

University of Wollongong,

Wollongong, NSW 2500,

Australia

I. Turco, R.P., Toon, O.B., Ackerman, T., Pollack, J.B.\& Sagan, C. Science 222, 1283-1292 (1983).

Teller, E. Nature 310, 62]-624 (1984).

\section{Bedlam at banquets}

SIR - At many international congresses phycological, entomological, and all sorts of others I've attended in recent years the value and pleasure of the closing dinners have been considerably reduced by noise. Bands and comedians, however good, and however appropriate for youth or political rallies, are out of place at scientific meetings, particularly on the final evening which may be the last (or even the only) occasion for congenial and informal discussions.

Musicians and other entertainers, with their inevitable kilobel amplifiers, should not be included in the programmes on such occasions. Communication is hard enough as it is, especially for the partly deaf, or for Finns and Turks trying to discuss technical matters in English with Japanese and Chinese colleagues who have gathered, often at considerable expense, perhaps for the only occasion in their lives; gratuitous noise makes it harder. There is a place and a time for entertainers, but not at conferences which we attend principally for the business of conferring.

Organizers, please note.

RALPHA. LEWIN

Scripps Institute of Oceanography,

University of California, San Diego,

La Jolla, California 92093, USA

\section{Plight of UK scientists}

SIR - The plight of Indian scientists (Nature 8 November, p.87) should not blind us to the problems which British scientists have long faced. In the words of your leading article, India has had a government whose policy for science had open and straightforward objectives, namely that understanding the natural world would in due course be a source of economic prosperity, social improvement and the banishment of superstition. Britain, by contrast, has a government which has looked mainly to immediate industrial benefits from science, and has adopted a policy towards higher education that is resulting, whether the government realizes it or not, in the Dissolution of the Universities. Research has not only been stultified by lack of funding in other than a few favoured subjects, especially in our universities which should be the powerhouses of research, but has also been subjected to policy planning which, by its very nature, cannot but direct resources and effort to the last problem instead of the next one. Desperate though the need for improved financial support is, it is even more vital to return to the tested and timehonoured Haldane principle in research.

Perhaps the international scientific community can indeed help science in India, but reciprocally science in Britian would be enormously helped if our national decision-makers were to learn from India.

Peter Fellgett

Department of Cybernetics, University of Reading, Reading RG6 $2 A L, U K$

\section{Peer review}

SIR - Surely, if a "considerable element of chance is an inescapable component of today's review procedures'' (Bryn Bridges, Nature 4 October, p.406), then the system should have been designed to take account of this random element. For example, the sharp cut-off point in the rank order when funds are exhausted would be blunted if there were a sliding scale of funding. Progressively less outstanding applications would receive progressively less than the optimum funds required to complete the project in a reasonable time. Applicants would then have to modify or slow down the rate of work. At least the entire project would not collapse. The peer review system was designed in the "good old days", when virtually any good application was sure of being funded. The system has failed to adapt to the realities of funding today's research ${ }^{1,2}$

Department of Biochemistry,

D.R. FORSDYKE

Queen's University,

Kingston, Ontario, Canada, K7L 3N6

Osmond, D.H. J. Neurobiol. 14, 95-112 (1983)

Forsdyke, D.R. Med.Hypoth.11, 141-156 (1983) 